\title{
The Solution of Applied Problems of Optimization of Stability of System "Environment-Man-Technics"
}

\author{
Nadegda Savelyevna Sevryugina ${ }^{1}$, Svetlana Borisovna Melikhova ${ }^{1}$ \& Eugene Alexandrovich Volkov ${ }^{1}$ \\ ${ }^{1}$ Belgorod State Shukhov Technological Universit, Belgorod, Russia \\ Correspondence: Eugene Alexandrovich Volkov, Belgorod State Shukhov Technological University, Belgorod, \\ 308012, Russia. E-mail: mtrushin@mail.ru
}

\author{
Received: October 16, 2014 Accepted: October 26, 2014 Online Published: January 11, 2015 \\ doi:10.5539/mas.v9n3p200 URL: http://dx.doi.org/10.5539/mas.v9n3p200
}

\begin{abstract}
Justified the application of the basic principles of the theory of dynamical systems in the study of the elemental balance of system "environment-man-technique" (EMT). It is established that the irreducibility of the system properties to the sum of the properties of its constituents leads to contradictions. The aim of the research is the development of methods to detect contradictions in the system EMT by assessing the consistency of its elements. The methodological base of the adopted theoretical generalization of scientific provisions of the leading scientists of the industry, constituting the content of the theory of machines. When solving the tasks, we used methods of systems theory, the theory of mathematical statistics, the theory of risk and catastrophe theory, methods of similarity and dimensions. Empirical dependences were based on regression analysis and are presented in the dimensionless form. In the process of research assessed the consistency of the elements for an idealized systems, which offered the reference indicators of their energy sustainability. Considered the behavior of each element of the system for the whole period of the life cycle in real conditions, obtained graphic dependences. The revealed contradictions in the interaction elements of the system EMT showed that current tasks, manmade and implemented technical means lead to the loss of stable equilibrium inside the "environment", which in turn affects the balance of life-support of the person item, evidence in the form established that in both cases, a loss of equilibrium state calls a "technique". Developed histogram situational assessment model perturbation in the system EMT can not only set the emerging element of contradiction, but also to develop a model of governance that ensures the balance of the elements of the system with a high level of security.
\end{abstract}

Keywords: system, element, people, technology, environment, safety, interactions, viability, contradictions

\section{Introduction}

The manufacturer entire life cycle support of road and construction machines (RCM) determines the all levels safety for the individual and society and is a decisive factor in creation the industry development strategy. The methodology and methodological support of RCM security study throughout their life cycle in specific operating companies (using the example of specific models) will reveal the strengths and weaknesses of the organization and hence form a set of measures to solve them (Verigin \& Tolstenev, 2007; Sevrjugina et al., 2012).

Equilibrium of the system "environment-man" is possible basing on principles of elemental mutual assistance, livelihood for "man" and resilience for "environment". This principle is realized in the life cycles of equipment maintenance process, road and construction machines, and can be provided at the stage of technical safety of their operation in the sphere of economic activity, in particular, road - building complex. Analysis of the current situation prevailing in many Russian machine-building enterprises, suggests that to meet the most security requirements of RCM factors related to the performance of targets and their technological perfection in all stages of their life cycle are essential (Sevrjugina, 2011).

Research Objective: working out methods to identify contradictions in the system EMT by assessing the consistency of its elements.

\section{Materials and Methods}

Methodological basis of the study is: theoretical generalization of scientific statements by industry leading scientists that constituent the content of the machines theory. Methods of systems theory (Nicolis and Prigogine, 1979; L. von Bertalanffy, 1962), the theory of mathematical statistics (Aivazian et al., 1985; Bershad, 1981; 
Storm, 1970), the theory of risk and theory of catastrophe (Poston, 1980; Henley \& Kumamoto, 1984), methods of similarity and number of dimensions (Venikov, 1964) were applied in solving the tasks in hand. Empirical relationships were based on regression analysis and presented in dimensionless form (Vnuchkov et al., 1987; Schenk et al., 1972).

\section{Informative Part}

The main challenges of effective road-building complex technical support is not only RCM constructive perfection, but the safety improving for all stages of the life cycle (LC).

Magnitude of the problem of safety control RCM requires the development and implementation of works complex and organizational and technical measures in view of the variety of physical processes decreasing the security in system "environment-man-technique".

When considering the problem primarily work has been done to establish the existing scientific reserve , assessing the effectiveness and applicability of the results of leading scientists research in the field of operation of construction and road machines, and in related industries (Sevrjugina et al., 2013; Newman et al., 2008).

It was determined that the solution of the problem should not be limited by specifics of the industry, the modern scientific theories and their tasks may have additional application in related fields. On the basis of this conclusion, the deduction was drawn on the application of a multidisciplinary approach assessing issues of technical safety of road and construction machinery at all stages of their life cycle.

Conceptually, a multidisciplinary approach allows us to consider the multiplicity of relationships and their variability while building the infographic system model "enviroment-man-safety- technique" (EMST).

The category of marginal component should include the indicator that takes into account the economic links (organizational and managerial), i.e. economics because the system under consideration was generated and can only be operated at the economic structure of society.

Justification of the proposed concept of multidisciplinary approach from a scientific point of view is consistent with the infographic model of system "environment-man-technique" proposed by Chulkov V.O. (Chulkov, 2003). Adopted indicator of its criterion takes into account the adaptive complex security assessment based on the following principles (Zorin et al., 2009):

- common to all mankind: the absolute priority of the life and health protection;

- technical: the availability of reliable tools for emergency management; presence of an optimum number of technical means for the protection of property;

- technology: quick response to the threat of an emergency; safety measures should not interfere with the technique in normal operating conditions and in the exercise of his human activities (Shang et al., 2011; NATO, 2001);

- economic: all safety measures should be low-cost. The justifiability of using infographic modeling due to the fact that it is possible to extend the classical model, in which man is usually distinguished as accented components (Kosuge et al., 1993). As reality has shown, that makes the limited perception of the importance of the component "environment", translated into the category of marginal.

It seems that the EMST system proposed for study inhere variability of accented components. In turn that requires additional scientific elaborations and making the adjustments to existing theory.

The analysis allowed to develop an algorithm to search for effective scientific achievements considering the hierarchical structure of human activities at the regional level (in places of his settlements: metropolis, regional level cities, rural settlements, etc.). 


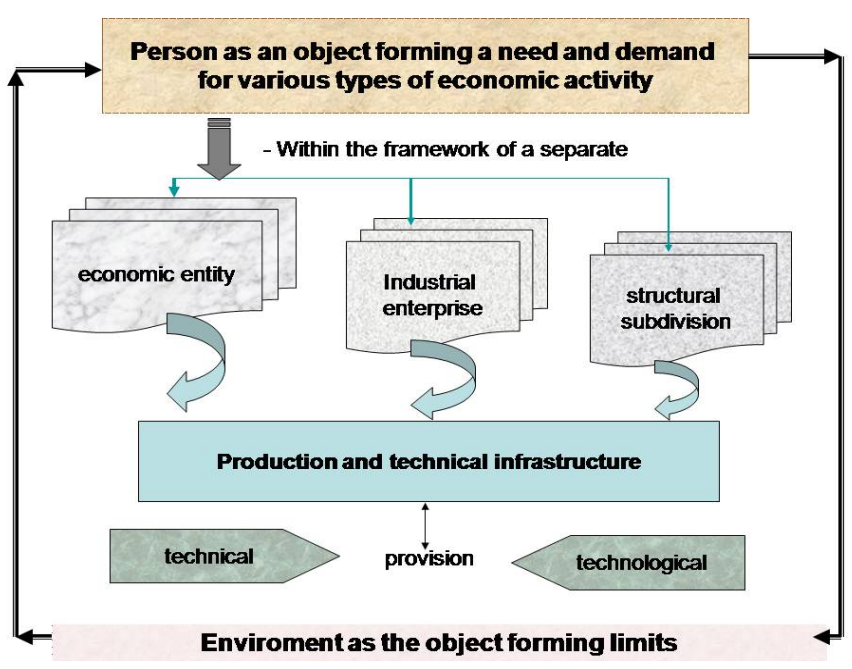

Figure 1. Algorithm of EMST system interference and structural saturation

It is established that the existence of a society is based on a variety of economic activities, which in turn require appropriate technical and technological support. Technical equipment for a sphere of road, industrial and civil engineering is provided by different types of road, construction, hoisting machines. And the result of their economic activities depends on their functionality and technological organization (Johannsen et al., 1992; Alty \& Johannsen 1989).

Proposed by scientists scientific approaches associated with the formation of service industries strategic competitiveness have many different interpretations. In turn this points to the need for additional, and in some cases new approaches taking into account the current trends of innovative technological development and its specific application in human activities.

Classical research for road, construction and hoisting machines is represented in the diagram (Figure 1). Although it involves problem solving by optimization synthesis, but does not defines explicitly interference in the EMST system despite the innovative development of the engineering and technology sphere. It confirms the need for a multidisciplinary approach in research activities with the release of the "safety" element in the system as a key and vital element for man and his environment.

Let us carry out the analysis on an idealized system, where there is no adverse impact between the elements, i.e. there is no contradiction, full reciprocity is provided. We can conclude that such a system should be invariant and equilibrium. All internal and external factors impact do not violate the stability of the system.

Further arguments require to assess coherence of the system, i.e. develop a method of identifying contradictions.

- functional (surface);

- parametric (depth);

- structural (sharpened)

To establish the boundaries of balance, or factors causing controversy.

Three groups of contradictions are sticked out:

Superficial contradiction for EMT system is characterized through the concept of "a need - an opportunity" in which accented component for the "need" element of the system acts - a man going into a marginal component of elements "environment" , "equipment" "function". It should be clarified that the element of "environment" feature "function" turning into a viability, and now more of a "durability", while the element of "technique" the feature "opportunity" is characterized by functional and technological perfection of machines.

Indicator for surface contradictions for idealized equilibrium of EMT system is deemed equal to zero, i.e. equilibrium is provided $K_{E M T}^{I}=0$ if idealized energy stability benchmarks are equal to unity, i.e.

$K_{E}^{I}=1$ - viability is not impaired;

$K_{M}^{I}=1$ - human need is satisfied in full;

$K_{T}^{I}=1$ - appliances provides human need functionally without breaking the viability of the habitat. 
Let us consider the behavior of each element of the system for the entire period of the life cycle in the real-life environment.

\section{ENVIRONMENT}

Quantitatively indicator of real conditions of existence sustainable equilibrium is taken in the range $0<K_{E}^{R}<1$. It indicates a decline in the viability of the environment in the EMT system.

Environment stability depends on factors of external influence, i.e. the more perfect the technique, the less impact it has on the environment in the implementation of the "need" feature for a system element "man".

Given that the surface contradictions may take some time to become apparent, we introduce the concept of "a manifestation of the deferred time contradictions effect", expressed in the emergence of the urban areas development prospects and their involvement in the economic activities of man, leading away from primordial (natural) existence:

- Short-term reaction of the environment;

- Medium-term reaction of the environment;

- Long term environment reaction

Let us demonstrate the above mentioned arguments in a graphical form, Figure 2.

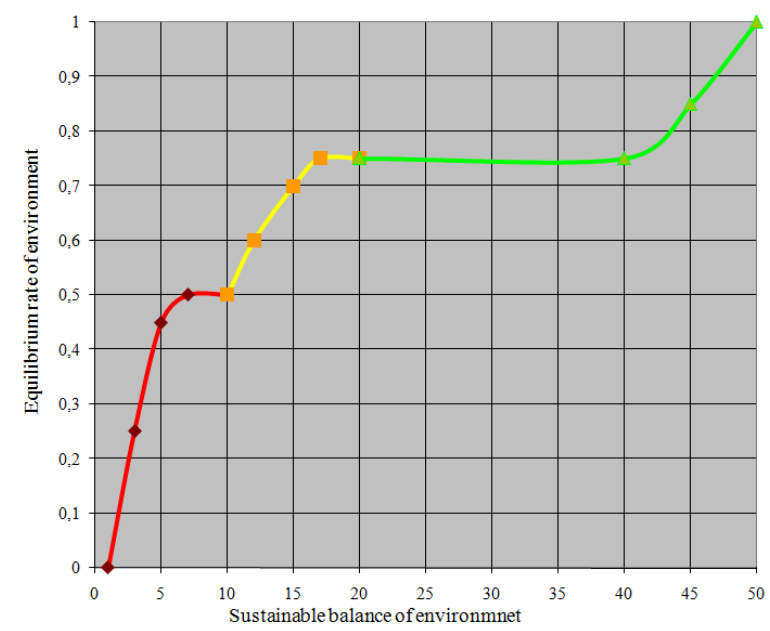

Figure 2. Dependence of the index $K_{E}$ alteration over time at different levels of coherence of the EMST system elements

For the environment it is required to allocate exposure periods to obtain the value of deferred time negative effect impact on the environment for the realization of human "needs" expressed by fulfillment of technological process, a period of environment reaction: flora; fauna, its ability to restore the upset balance.

It is logical to conclude that in the considered case in the time range of 50 years the environment balance is provided by reducing impact of technology and person, particularly index of stable equilibrium:

$K_{E}^{F}=0,75 \ldots 1$ - superficial contradiction for restoring the balance during 1 year followed by maintenance activities up to 4 years to ensure conservation of the environment on a 10-year period;

$K_{E}^{F}=0,5 \ldots 0,75$ - intensified contradiction requiring a rebalancing 5-year period oriented program, followed by maintenance activities up to 8 years to ensure environmental conservation on a 20 -year period;

$K_{E}^{F}=0 \ldots 0,5$ - sharped contradictions where the imbalance requires long-term rehabilitation program (5-16 year period), and 50 -year-old rehabilitation.

\section{MAN}

In the EMT system man safety aspect affects rather human socio-economic and ethical norms, i.e. his comfort and vitality. Let us consider this statement in more detail.

Factor analysis identifies indicators of external and internal exposure and the nature of their relationships. In our idealistic model man is the object included in the system, but he does not influence it and he is not the object providing the implementation of a technological process while driving technique in realization of established 
function named "need".

It should first be noted that the road and construction machines operator can be estimated by the psychophysical and anthropometric indicators (Kirichenko, 2002; Salvendy, 2006). The equilibrium state is provided by the following features: RCM operator experience, his skills, discipline, the ability to make quick decisions in emergency situations and to anticipate and act in terms of preventing them (1986; Banks 2005; DoD 1968; Ignatiev et al.).

The EMT system indicator deemed stable equilibrium for the person is easier to interpret as an indicator of comfort with a range of values of $0<K_{M}^{E}<1$.

Basic characteristics of the element "man" in EMT system implicate age - experience - the reaction.

Time period of comfort indicators is selected based on the period from attainment of 21 , after which he has the ability to manage the RCM to retirement period, for men - 60 years.

The concept of "experience" means ability to manage the RCM on the reflex level attained by the continuous improvement of management skills RCM , it should be noted that this does not take into account the personal characteristics of the operator are taken averaged data.

In turn, the concept of "reaction", though depend entirely on experience, but with age it is reduced in humans, by virtue of psycho-physiological features. Also we do not consider here the psycho-emotional state and its constant change.

The above mentioned leads to the conclusion that as accented component in the EMT system element "technique" should be selected, due to the fact that this element is formed by a man and the kind of exerted influence on the environment depends on his technical mastery.

Perfectly constructed machine model providing maximum comfort and ease of operation for the operator, with minimal impact on the environment after the execution of the process is taken for a unit value. Consequently, for the same range of values of index $0<K_{T}^{R}<1$, a zero value points to a mechanical system that does not meet the requirements of safety, environmental compatibility, efficiency and functionality.

Summarizing the above written, we propose an estimative mathematical model of the disturbance impact value in the EMT system:

$$
K_{E M T}=\left(1-\frac{K_{E}^{R}}{K_{E}^{I}} \cdot \frac{K_{M}^{R}}{K_{M}^{I}} \cdot \frac{K_{T}^{R}}{K_{T}^{I}}\right)
$$

Using situational simulations we have determined the effects of disturbance in the EMT system with the specified base value of the environment state and variable values of the level of technological state and of the art and human comfort index.

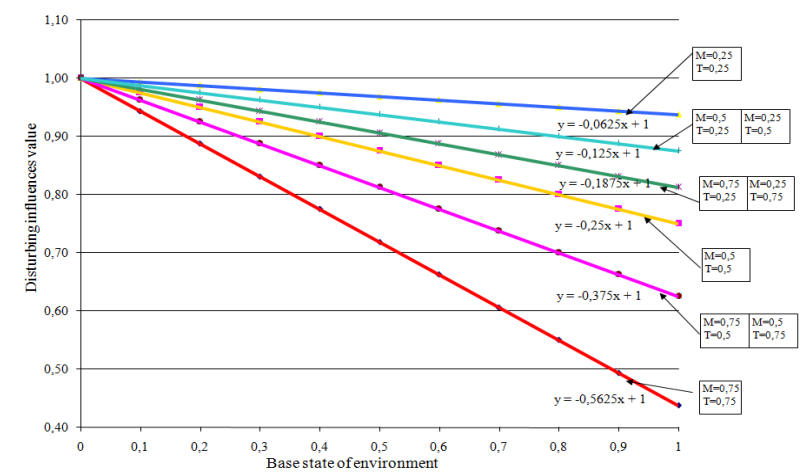

Figure 3. Situational assessment modeling of disturbances in the system of "environment-man-technique"

The graph shows that for the system simulation model of a perfectly balanced environment, with the $K_{M}^{F}=0,75$ and $K_{T}^{F}=0,75$ magnitude of disturbances for implementation of the "need" function would entail significant changes $K_{E M T}^{F} \approx 0,4$ (Figure 3).

Developed situational disturbances assessment model histogram in the system "environment-man-technique" allows us not only to establish the emerging element contradictions, but also to develop a management model 
providing a balance of system components with a high level of security.

The obtained values of disturbances are a converse function to integrated security system

$$
K_{E M S T}=\frac{1}{K_{E M T}}
$$

In the work (Glagolev and Starikova, 2012), it is suggested to correlate cooperation in ET system with ratio

$$
O_{c} K_{C}=\text { const },
$$

where

$O_{c}$ - the environment organization;

$K_{C}$ - the complexity of the machine as a whole,

i.e. while developing a specific machine to find a compromise between the two options: invest in the environment organization, adapting it to the element system "machine", or create a highly adaptive machine.

The above deduced dependences prove insolvency of the first possibility. In our opinion the author (Verigin \& Tolstenev, 2007) does not include the most significant component of the "man" in this system.

In a modified form the ratio for the EMT system deemed to take the following expression:

$$
O_{c} K_{C} C_{M}=\text { const }
$$

where

$C_{M}$ - the ability to manage human impact on the machine.

This figure includes both physical person capabilities, and the technical capabilities of the machine, that are generalized by the transmitted information stream.

By analogy, one can write the formula of relation between the level of information transmitted while manipulating the machine and complexity degree of perception of flow.

$$
I K_{C}=\text { const }
$$

where $I \approx C_{M}$ - the level of structural (or configuration) information.

Analyzing variants of the parameters alteration of the formula it is reasonable to assume some extremes:

- if $I \rightarrow 0$ there is no flow of information, making it impossible to control the machine;

- if $I \rightarrow \infty$ regarding an excess of information flow, constructive machine perfection tends to 0 ;

Accordingly system can be created hypothetically. This system does not need to be assembled with additional tools and machines, i.e. it is self-organizing, which is consistent with the rapidly developing scientific field Synergetics. Currently, advanced technical systems, means in our case, road and construction machines develop as a coordinated and coherent system, but it does not eliminate arising contradictions problems: the first is the desire for information-intensive technologies (the utmost case $I \rightarrow \infty, K_{C} \rightarrow 0$ has serious limitations that lie far from the point $\left.K_{C}=0\right)$; second - the machine can not infinitely be improved so that it can convert any technology $\left(I \rightarrow 0, K_{C} \rightarrow \infty\right)$.

Selected contradictions are contradictions between specialization and versatility of modern machinery and technology in general. The first contradiction leads to the only occurence of specialized machines, second - says that there should be need to strive for technology universality, i.e. should solve the problem of the rational coherence of both.

\section{Discusission}

In essence, the above reasoning leads to the conclusion that a multidisciplinary approach to the study of EMST conform on the legislative level with the requirements outlined in the laws "On technical regulation", defining the legal framework of governing the relations arising in the development, adoption, application and performance of the mandatory requirements (on a voluntary basis) for products, processes of production, operation, storage, transportation, marketing and utilization; performance of work or provision of services; and conformity assessment. As a goal in the "Certification Requirements" mark (Sevrjugina et al., 2013, Federal law, 2002):

- improving the life or health safety of citizens, property of individual or legal entity, public or municipal property, environmental safety, life or health of animals and plants safety, and compliance with the requirements 
of technical regulations promotion;

- improving facilities security level with regard to the risk of natural and man-made emergency situations;

- providing scientific and technical progress;

- improving the competitiveness of products, works and services;

- rational use of resources;

- technical and information compatibility;

- comparability of researches (tests) results and measurements, technical and economic and statistical data;

- products intersubstitutability.

It should be noted that statutorily, while developing specific technical regulations provision is made for the application of risk theory as a base for establishing safety requirements for certain types of machinery and equipment and certain stage in their life cycle (Salvendy 2006, ISO, 2003).

For economic entities it is provided to use the results of risk analysis, including:

- enterprises manufacturers while justifying technical solutions to ensure the safety of the machinery and/or equipment, for insurance;

- enterprises operators when making the safety economic analysis on criteria "value - security - benefit", assessing the impact of economic activities on the environment and other procedures related to the safety analysis.

\section{Consclusion}

It has been found that the implementation of society needs through intensive development of techniques and technologies aimed at person subsistence reduces the viability of human environment, compromising the integrity of the system "man-environment" that requires further research to develop a strategy for systemic equilibrium.

It is proved that the irreducibility of system to the sum of the properties of its elements leads to contradictions.

Assessed the elements coherence of idealized system, resulting in the proposed benchmarkable values of energy sustainability. The behavior of each element of the system for the entire period of the life cycle in the real conditions has been studied, graphic characteristic curves have been got.

Considered contradictions in reciprocal action of EMT system elements revealed that current tasks posed by man and implemented with technical means lead to a loss of stable equilibrium inside the "environment", which in turn affects the balance of life support of element "man", in both cases, loss of equilibrium causes element "technique".

Developed histogram of situational assessment model of disturbances in the EMT system allows not only to estimate the arised elemental contradictions, but also to develop a management model providing a balance of system components with a high level of security.

\section{References}

Aivazian, S. A., Anyukov, I. S., \& Meshalkin, L. D. (1985). Applied statistics: the Study of dependencies. Mosocw: Finance and statistics.

Alty, J. L., \& Johannsen, G. (1989). Knowledge based - dialogue for dynamic systems. Automatica, 25, 829-840. http://dx.doi.org/10.1016/0005-1098(89)90051-4

Banks, J., Carson, J. S. II., Nelson, B. L, \& Nicol, D. M. (2005). Discrete-event system simulation. China Machine Press, Beijing, China, 99-128.

Bershad, L. I. (1981). Self-organization and reliability of tribosystems. Kiev: Knowledge, p. 218.

Bertalanffy, L. V. (1962). General System Theory—A Critical Review. General Systems, VII, 1-20.

Chulkov, V. O., Greaph, M. I., Kazaryan, R. R., Masterov, I. Y., \& Smirnov, P. N. (2003). Life safety. Organizational-antropologicheskaya reliability of functional systems of mobile environment building production. Moscow: Publishing house of the DIA, p. 176.

DoD. (1968). Missile systems human factors engineering criteria. MIL-STD-1248, Department of Defense, USA.

Federal law of the Russian Federation “On technical regulation” of 27.12.2002 Volume 184-FZ. 
Glagolev, S. N., \& Starikova, M. S. (2012). Cognitivity demand management as a reaction of the Corporation to the new economic conditions. Bulletin of BSTU named after V.G. Shukhov, 3, 99-102.

Henley, E. J., Kumamoto, H. (1984). Reliability of technical systems and risk assessment. Moscow: Mashinostroenie.

Ignatiev, M. B., Ilevskoy, V. Z., \& Closures, L. P. (1986). Modelling of machines. St. Petersburg: Mashinostroenie. Leningrad., p. 304.

International Organization for Standardization (ISO). ISO 14649-1, Industrial automation systems and integration - Physical Device Control - Data model for computerized numerical controllers Part 1: Overview and fundamental principles, 2003.

Johannsen, G., Levis, A. H., \& Stassen, H. G. (1992). Theoretical problems in man-environment system and their experimental validation. Man-Machine Symposium (issue 31), GMU, p. 124.

Kirichenko, I. G. (2002). The modular design concept of technological machines for construction processes. Kharkiv: Publishing house of KHNADU, p. 119.

Kosuge, K., Fujisawa, Y., \& Fukuda, T. (1993). Mechanical system control with man-machine-environment interactions. Robotics and Automation. International Conference. Atlanta, GA (issue 1), IEEE, 239 - 244.

NATO (2001). Guidelines on human engineering testing and evaluation. NATO RTO-TR-021, North Atalantic Treaty Organization

Newman, S. T., Nassehi, A. X., Xu, W., Rosso, R. S. U., Wang, J. L., Yusof, Y., Ali, L., ... Dhokia, V. (2008). Strategic advantages of interoperability for global manufacturing using CNC technology, Robotics and Computer-Integrated Manufacturing, 24(6), 699-708. http://dx.doi.org/10.1016/j.rcim.2008.03.002

Nicolis, G., \& Prigogine, I. (1979). Self-organization in nonequilibrium systems. Moscow: Mir, p. 213.

Poston, T. (1980). Catastrophe theory and its applications. Moscow: Mir, p. 608.

Salvendy, G. (2006). Handbook of human factors and ergonomics. John \& Sons, Inc., Hoboken, New Jersey, USA. http://dx.doi.org/10.1002/0470048204

Schenk, H. (1972). Theory of engineering experiment. Moscow: Mir, p. 381.

Sevrjugina, N. S. (2011). Infographic model of complex safety of transport and technological machines work safety in industry. Industrial safety journal, 6, 72-74.

Sevrjugina, N. S., Prokhorova, E. V., \& Dikevich, A. V. (2012). Simulation of emergency situations when assessing the reliability of machinery. Bulletin of the Kharkov National Automobile and Highway University. Collection of scientific works, 57, 90-97.

Sevrjugina, N. S., Prokhorova, E. V., \& Dikevich, A. V. (2013). Risk assessment of emergencies during operation impact machines. Bulletin of BSTU named after Shukhov, V. G. 2, 192-195.

Shang, Z., Qiu, C., \& Zhu, S. (2011). A model of application system for man-machine-environment system engineering in vessels based on IDEF0. Journal of Marine Science and Application, 10(3), 347-357. http://dx.doi.org/10.1007/s11804-011-1079-9

Storm, R. (1970). Probability theory. Mathematical statistics. Statistical quality control. Moscow: Mir.

Venikov, V. A. (1964). Fundamentals of the theory of similarity. Moscow: Energya, pp. 64.

Verigin, U. A., \& Tolstenev, C. C. (2007). Synergistic framework of processes and technologies. Barnaul: ASTU publishing house, p. 160.

Vnuchkov, I., Boyadjieva, L., \& Solakov, E. (1987). Applied linear regression analysis. Moscow: Finance and statistics.

Zorin, V. A., Deguello, V. A., \& Sevrjugina, N. S. (2009). Safety requirements to ground-based transport systems. Belgorod: Publishing house of BSTU named after V. G. Shukhov, p. 186.

\section{Copyrights}

Copyright for this article is retained by the author(s), with first publication rights granted to the journal.

This is an open-access article distributed under the terms and conditions of the Creative Commons Attribution license (http://creativecommons.org/licenses/by/3.0/). 